REVISTA DE DERECHO UNED, NÚM. 28, 2021

\title{
INCONGRUENCIAS DE UN SISTEMA REHABILITADOR: SEVERIDAD, CIFRAS, LIMITANTES Y ALTERNATIVAS
}

\author{
INCONSISTENCIES IN A REHABILITATION SYSTEM: \\ SEVERITY, FIGURES, LIMITATIONS, AND ALTERNATIVES
}

\author{
Pablo D. Punín TANDAZo ${ }^{1}$
}

Sumario: I. Introducción. II. Situación actual del Sistema de Rehabilitación en Ecuador. III. Reformas legislativas y cifras. IV. Sistema alternativo de penas. IV.1. Contexto España: Suspensión de la pena y trabajo en beneficio a la comunidad. IV.1.A. Suspensión de la pena. IV.1.B. Trabajo en beneficio de la comunidad. IV.2. Contexto Ecuador: suspensión condicional de la pena y trabajo en beneficio de la comunidad. Suspensión condicional de la pena. IV.2.A. Trabajo en beneficio de la comunidad o sanción comunitaria. V. Conclusiones: las incongruencias. VI. Metodología. VII. Limitaciones. VIII. Bibliografía.

Abstract: This article makes an approximation to the current situation of the Ecuadorian prison reality, taking the existing figures as a basis to show that the solutions proposed haven't had positive results. The effects of the punitive policy applied to the most perpetrated crime in Ecuador (robbery) are analysed and evaluated to determine if there has been an incidence between what was

\footnotetext{
1 Abogado por la Pontificia Universidad Católica del Ecuador en el año 2018. Máster en Criminología y Ejecución Penal por la Universitat Pompeu Fabra en el año 2020. Actualmente cursando la Escuela Alemana de Ciencias Criminales de la Universidad de Göttingen. Especialista de Patrocinio en el Área Penal de la Dirección Nacional de Patrocinio de la Contraloría General del Estado de Ecuador. Coordinador y miembro fundador del Observatorio de Criminología, Política Criminal y Ejecución Penal de Ecuador. Docente tutor en la Universidad Tecnológica Empresarial de Guayaquil (UTEG). Investigador jurídico independiente.
} 
executed and the reduction in crime regarding to this offense. In the same way, the need to seek different solutions to pure punitivism is exposed, using the failure of prison as a starting point and the analysis of an alternative system of penalties with its effects in a comparative reality. Specifically, alternative figures to prison applicable in the Spanish reality are considered, such as: the suspension of the sentence and work for the benefit of the community. The use of these figures in Spain and Ecuador is studied, so that the main differences in the legal margins of application can be observed. In addition, there is a brief mention of the effects that they have had on the reality of the Iberian country and its contribution to the decongestion of the prison system.

Resumen: En el presente artículo se hace una aproximación a la situación actual de la realidad carcelaria ecuatoriana, tomando las cifras existentes como base para evidenciar que las soluciones planteadas no han tenido efectos positivos. Se analizan y evalúan los efectos de la política punitiva aplicada al delito más perpetrado en Ecuador (robo), para determinar si existió incidencia entre lo ejecutado y la reducción de criminalidad respecto a este delito. De igual forma, se expone la necesidad de buscar soluciones distintas al punitivismo puro, utilizando como partida el fracaso de prisión y el análisis de un sistema alternativo de penas con sus efectos en una realidad comparada. En concreto, se toman en cuenta figuras alternativas a la pena privativa de libertad aplicables en la realidad española, como lo son la suspensión de la pena y el trabajo en beneficio de la comunidad. Se estudia su uso en España y Ecuador, de manera en la que se pueden observar las principales diferencias en los márgenes legales de aplicación. Además, se hace una breve mención a los efectos que han tenido las mismas en la realidad del país ibérico y su contribución a la descongestión del sistema carcelario.

Keywords: Alternative measures to prison, conditional suspension of the sentence, community sanctions, work for the benefit of the community, prison overcrowding, recidivism, robbery.

Palabras clave: Medidas alternativas a prisión, suspensión condicional de la pena, sanciones comunitarias, trabajo en beneficio de la comunidad, sobrepoblación carcelaria, reincidencia, robo.

Recepción original: 03-06-2021

Aceptación original:28-09-2021 


\section{INTRODUCCIÓN}

El sistema penitenciario ecuatoriano ha sufrido una constante debacle respecto a su capacidad de tratamiento de personas privadas de libertad. El hacinamiento en las prisiones ecuatorianas se ha convertido en un problema de máxima prioridad que ha derivado en una ola de violencia desatada en el interior de los centros de rehabilitación ${ }^{2}$.

El foco de atención se ha centrado en el uso excesivo de la figura de prisión preventiva como responsable del crecimiento de la población penitenciaria ${ }^{3}$. Sin embargo, parece que esta explicación se ha quedado corta al no encontrar una vía eficaz e idónea para combatir este problema. Es por esto que, en este artículo, se buscan demostrar dos puntos: 1) El endurecimiento de penas no ha servido como mecanismo para combatir la criminalidad; y, 2) La necesidad de acudir a soluciones distintas y coherentes entre sí.

Las cifras y los datos existentes han servido de fundamento para evidenciar la ineficacia de una política criminal punitiva. Por otro lado, la falta de coherencia y armonía normativa materializada en las distintas contradicciones que existen en nuestro código penal, obstaculizan la posibilidad de dar nuevas alternativas para afrontar las limitantes existentes en el sistema de rehabilitación social. El problema radica en que se trata de brindar nuevas soluciones, sin alejarse del punitivismo en absoluto.

La consagración de un sistema alternativo de penas que tiene como finalidad reducir el uso de prisión no es suficiente por sí mismo para la consecución de los objetivos esperados. De poco sirve su introducción en nuestra legislación, si las penas de los delitos van

2 En Ecuador se utiliza la denominación "centros de rehabilitación" como sinónimo de prisión debido a los fines establecidos para esta institución en el Código Penal y la Constitución.

3 Distintos estudios se han enfocado al uso de la prisión preventiva y su correlación con problemas estructurales dentro de las cárceles. Al respecto se puede ver: FLORIAN, A. La prisión preventiva en el Ecuador, Quito: Defensoría Pública, 2018. ISBN 978-9942-9905-2-5; DEFENSORÍA DEL PUEBLO. Informe temático sobre la prisión preventiva desde la prevención de la tortura y otros malos tratos en el Ecuador, Quito: Defensoría del pueblo, 2018; ZALAMEA, D. Reporte del estado de la prisión preventiva en el Ecuador, Centro de Estudios de Justicia de las Américas, 2016; OEA. Informe sobre el uso de la prisión preventiva en las Américas, Columbia: OEA, 2013. ISBN 978-0-8270-6096-8; entre otros. Además, el exdirector de Rehabilitación Social en Ecuador, Ernesto Pazmiño, manifestó que los problemas de hacinamiento tienen relación con el uso abusivo de la prisión preventiva. Esto último, tomado de: ¿Por qué hay tanta gente en las cárceles del Ecuador? [en línea] [12 de febrero de 2021]. Disponible en: https://gk.city/2019/08/13/tanta-gente-carceles-ecuador/ 
en aumento y los ejecutores del sistema penal no optan por utilizar estos mecanismos; ya sea por falta de conocimiento o voluntad.

En pleno siglo XXI, aún existen sociedades que mantienen en el último escalafón a quienes están dentro de prisión. Estas personas sufren la suerte de ser despojadas de su dignidad y son internadas en sitios que parecen adecuados solamente para causar sufrimiento. Sitios en donde el Estado tiene el control absoluto de vidas que poco le interesan. Recordemos este pequeño pasaje, vigente hoy en día, escrito por Norval Morris:

Las cárceles tienen escasos amigos; el descontento con ellas es cosa generalizada. Más que a menudo son escenario de brutalidades, violencia y conflictos raciales. Y en la medida en que las cárceles pretenden curar a los criminales de la delincuencia, su foja de servicios es poco alentadora. Sin embargo, las cárceles tienen otros objetivos: castigar, excluir, que les aseguran su permanente supervivencia ${ }^{4}$.

\section{SITUACIÓN ACTUAL DEL SISTEMA DE REHABILITACIÓN EN ECUADOR}

No se puede hablar del sistema penitenciario ecuatoriano sin mencionar la constante vulneración de derechos que ha existido en los interiores de sus centros de rehabilitación. No es reciente, estamos frente a un problema estructural que, pese a la distinta corriente ideológica que han tenido los gobiernos de turno entre sí, lleva arrastrándose y creciendo desde hace muchos años. La situación ha llegado a un punto tan crítico que en este año el mundo fue testigo de las peores masacres de la historia penitenciaria del Ecuador, dejando así un aproximado mayor a 200 personas privadas de libertad asesinadas en lo que va del $2021^{5}$. Este no es un incidente aislado, la ola de violencia que se da dentro de las cárceles ecuatorianas es constante, tanto así que, en los dos últimos años, el presidente tuvo que decretar estado de excepción en los centros penitenciarios del país

4 MORRIS, N. El futuro de las prisiones: estudios sobre crimen y justicia. Madrid: Siglo veintiuno, 1978. ISBN 13: 9789682300615

5 En febrero de 2021 los incidentes en prisión dejaron un aproximado de 79 personas asesinadas, en junio del mismo año los incidentes causaron un total de 22 personas asesinadas; y, en septiembre del mismo año los incidentes han reflejado un aproximado de 116 personas asesinadas. Es necesario enfatizar en que la cifra es más preocupante cuando se toma en cuenta las personas privadas de libertad que si bien no fueron asesinadas, sí fueron heridas. Adicionalmente, por la grave crisis que enfrenta el sistema penitenciario, no sorprendería que este número aumente en los próximos meses y años. 
por dos ocasiones ${ }^{6}$. Los problemas no han terminado ahí, pese a los distintos pronunciamientos contra la forma de gestionar las prisiones ecuatorianas y los esfuerzos en solicitar al Estado una solución eficaz e integral ${ }^{7}$, no ha existido un planteamiento que ataque el fondo del problema. Ejemplo de esto han sido los numerosos incidentes dentro de prisión posteriores a la masacre de febrero, como el abuso sexual de una funcionaria de prisión y el asesinato de 22 personas privadas de libertad; o, los motines en los centros de privación de libertad que han dejado varios heridos como resultado ${ }^{8}$, entre otros. La génesis de la vulneración sistemática de derechos dentro de los centros de rehabilitación tiene relación directa con la errónea gestión que se maneja en el sistema penitenciario ecuatoriano tanto en su forma, como en su fondo.

Uno de los principales señalamientos para determinar las causas de la violencia interna en las cárceles apunta al hacinamiento existente en Ecuador. El Comité Permanente por la Defensa de los Derechos Humanos señaló que en el país existe sobrepoblación carcelaria en un aproximado de 33\%, teniendo un sistema penitenciario con capacidad para 28500 personas en el que se encuentran cumpliendo condena, o esperando sentencia, más de $40000^{9}$. La población penitenciaria existente es alta en gran medida por la política punitiva que se ha ejecutado en el país como respuesta única a la criminalidad. Justamente, la población reclusa de un país depende de dos variables: el número de entradas en prisión y la duración de la estancia $^{10}$. Esta política punitiva se ve reflejada en el incremento de penas y la creación de nuevos tipos penales; en el uso abusivo de prisión preventiva, desnaturalizando su carácter extraordinario; en la escasez de un sistema alternativo de penas eficaz; y, en dejar a un lado

6 BBC News Mundo [en línea] [23 de febrero de 2021]. Disponible en: https:// www.bbc.com/mundo/noticias-america-latina-56186555.

$7 \quad \mathrm{Al}$ respecto puede verse el auto de fase de seguimiento 4-20-EE/21 y 6-20-EE acumulado de la Corte Constitucional del Ecuador, en el que se recalca el incumplimiento estatal para abordar el problema de las cárceles en el país y se insta al Estado a tomar medidas que ataquen el fondo del problema.

8 DW [en línea] [01 de agosto de 2021] Disponible en: https://www. dw.com/es/un-muerto-y-cinco-heridos-por-enfrentamiento-en-c\%C3\%A1rcel-deecuador/a-58719060; y, El Universo [en línea] [22 de julio de 2021] Disponible en: https://www.eluniverso.com/noticias/seguridad/se-reportan-disturbios-en-la-penitenciaria-del-litoral-nota/

$9 \mathrm{CDH}, \mathrm{C}$. P. Informe hacinamiento y violencia son formas de tortura, situación de derechos humanos de población carcelaria y su familia en contexto de Estado de Excepción. Guayaquil: CDH, 2019.

10 CID, J., \& LARRAURI, E. Penas alternativas a la prisión. Barcelona, España: BOSCH casa editorial s.a., 1997. ISBN: 84-7676-403-0 
los propósitos rehabilitadores y de reinserción social mediante el desamparo estatal a las personas privadas de libertad.

Este desamparo estatal se ha exteriorizado mediante la vulneración de derechos básicos a las personas privadas de libertad; misma que se puede evidenciar en los distintos actos de violencia que mencioné anteriormente, o en la falta de recursos que permitan un correcto funcionamiento del sistema de rehabilitación, logrando que el Estado falle ante su rol de garante ${ }^{11}$.

En esta línea, existió una reducción presupuestaria hacia las entidades rectoras del sistema penitenciario, generando así un gran obstáculo para la ejecución de sus proyectos, programas, e incluso la eficacia de su desempeño. Los datos del Servicio Nacional de Atención Integral de Personas Adultas Privadas de Libertad y Adolescentes Infractores del Ecuador (SNAI) visibilizan un poco la situación que se vive dentro de los centros de rehabilitación en este sentido. $\mathrm{Al}$ respecto, indican que: 1) En Ecuador un guía penitenciario debe cuidar en promedio 27 personas, cuando la recomendación internacional emitida por ONU y OEA es de al menos 1 guardia por cada 10 reclusos; 2) La escuela de formación de guías penitenciarios fue abandonada en el año 2017; 3) En el año 2019 el desembolso realizado a la institución fue solamente del $10 \%$ del total del presupuesto asignado; y, 4) Existen constantes denuncias respecto a las paupérrimas condiciones de vida dentro de prisión y el desabastecimiento de comida, agua y medicina ${ }^{12}$.

Como se puede evidenciar, las principales causas de la situación interna en las prisiones ecuatorianas son generadas por el mismo Estado. La suma de todas estas decisiones y su ejecución; así como, la omisión en plantear soluciones integrales y eficaces, han aportado a profundizar la gran crisis que enfrenta el sistema penitenciario ecuatoriano. La Comisión Interamericana de Derechos $\mathrm{Hu}-$ manos ha establecido que la naturaleza de los problemas de las

11 Véase: art. 31 de la Constitución del Ecuador; Comisión Interamericana de Derechos Humanos, Principios y Buenas Prácticas sobre la Protección de las Personas Privadas de la Libertad en las Américas. Washington D.C.: Organization of American States, 2008.; Corte IDH, Caso Neira Alegría y otros vs Perú, sentencia de 19 de enero de 1995; Corte IDH, Caso Juan Humberto Sánchez vs Honduras, sentencia de 07 de junio de 2003; Corte IDH, Caso "Instituto de reeducación del menor" vs Paraguay, sentencia de 10 de noviembre de 2009; Corte IDH, Caso De La Cruz Flores vs Perú, sentencia de 18 de noviembre de 2004; y, Corte IDH, Caso Tibi vs Ecuador, sentencia de 07 de septiembre de 2004.

12 PRIMICIAS [en línea] [26 de febrero de 2021]. Disponible en: https://www. primicias.ec/noticias/sociedad/carceles-tienen-deficit-setenta-por-ciento-guias-penitenciarios/ 
políticas públicas, en los distintos sistemas penitenciarios americanos, causa deficiencias estructurales que afectan gravemente derechos humanos inderogables dentro de prisión ${ }^{13}$.

\section{REFORMAS LEGISLATIVAS Y CIFRAS}

Los cambios legales que han existido en nuestra legislación penal son sumamente amplios, podría hacerse un estudio completo respecto a las reformas realizadas. Es por esto que, para facilitar el análisis, he decidido estudiar los cambios ejecutados en nuestro Código Penal concentrándome en los delitos mayormente perpetrados en el país y los efectos resultantes de su aplicación. Esto también en razón de los limitados datos existentes respecto a otros delitos, cuestión que dificulta la realización de un análisis en aspectos de reincidencia y materialización.

De los datos obtenidos, tal como expondré en los próximos párrafos, los delitos con mayor índice de materialización en Ecuador son los delitos contra la propiedad. El robo, en concreto, es el delito mayormente cometido y denunciado en Ecuador desde hace varios años. Esto se puede evidenciar en la última encuesta de victimización y percepción de inseguridad realizada por el Instituto Nacional de Estadísticas y Censos, en la que se puede observar que 17 de cada 100 personas han sido víctimas de algún delito, 14 de cada 100 personas han sido víctimas del delito de robo a personas y, 4 de cada 100 hogares han sido víctimas del robo a vivienda ${ }^{14}$.

Así mismo, en un informe realizado por el Ministerio Coordinador de Seguridad y Fiscalía General del Estado en el que se pueden observar los principales delitos cometidos en el Ecuador entre los años 2013 y 2014, se evidencia que el robo en sus distintas modalidades es el delito más denunciado, estando en primer lugar el robo a personas con un total de 5.711 denuncias. Recién en séptimo lugar de la tabla entra un tipo penal diferente, siendo el de violación con 834 denuncias $^{15}$. En contraste con algo similar -y al mismo tiempo

$13 \mathrm{CIDH}, \mathrm{C}$. I. Informe sobre los derechos humanos de las personas privadas de libertad en las américas. Columbia: Organización de Estados Americanos OEA, 2011.

14 Instituto Nacional de Estadísticas y Censos. Encuesta de victimización y percepción de inseguridad 2011 [en línea] [03 de marzo de 2021]. Disponible en: https://www.ecuadorencifras.gob.ec//documentos/web-inec/Victimizacion/Presentacion_principales_resultados.pdf

${ }_{15}$ Ministerio Coordinador de Seguridad y Fiscalía General del Estado. Delitoscopio, informe de delitos [en línea] [15 de marzo de 2021]. Disponible en: https://issuu.com/fiscaliaecuador/docs/libro_fiscalia_horizontal_publicado. 
siendo el dato que nos indica la ineficacia del endurecimiento de la pena de este delito- el INEC realizó la operación estadística correspondiente a las denuncias de delitos de mayor incidencia en el Ecuador desde el año 2014 a 2019, misma que arrojó como resultado que el robo - también en sus distintas modalidades- es el delito más denunciado año tras año; teniendo como principal el robo a personas con un promedio de 30.641 denuncias por año. Aquí vemos nuevamente recién en séptimo lugar un delito distinto (violación) con un promedio de 5.035 denuncias por año ${ }^{16}$. Lo interesante de este último dato es que el índice de cometimiento y denuncias de este delito se han mantenido estables en el tiempo; por lo que, se puede entender que cualquier cambio o política aplicada a prevenirlo no ha sido fructífera al no generar incidencia estadística.

Este tipo penal se encuentra consagrado en el artículo 189 del Código Orgánico Integral Penal —en adelante COIP - y para configurarse se necesita que una persona, mediante amenazas o violencia, sustraiga o se apodere de cosa mueble ajena, admitiendo la posibilidad de imponer una pena privativa de libertad de 5 a 7 años.

En este punto es importante señalar que nuestra legislación penal advirtió diversos cambios en la materia con la promulgación del COIP en el año 2014. Una de ellas - y pertinente al caso- fue el aumento en la pena del delito de robo, tratando de encontrar una solución al cometimiento de esta conducta desde una política criminal que apeló al aumento y severidad de la pena para la prevención del mismo. En el ex código penal de 1971 la pena del delito era de 1 a 5 años, otorgando reclusión menor de 3 a 6 años en caso de ser con violencia contra las personas, tomando en cuenta el valor de las cosas robadas ${ }^{17}$.

A más del endurecimiento de penas en varios delitos, los cambios realizados con la vigencia del nuevo código penal también abarcaron ámbitos procesales y de fondo, como las finalidades de la pena y la introducción de un sistema alternativo de penas, cuestiones a las que me referiré más adelante.

Las reformas no terminaron con la promulgación del COIP, sino que, este cuerpo normativo también ha sido reformado con el pasar del tiempo. Siendo importante indicar en este punto que no considero erróneo ejecutar cambios; lo que sí me parece equivocado, por otro lado, es que estos cambios no tengan un sustento técnico

16 Instituto Nacional de Estadísticas y Censos. Denuncias de delitos de mayor incidencia [en línea] [ 17 de marzo de 2021]. Disponible en: https://www.ecuadorencifras.gob.ec/justicia-y-crimen/

17 Artículo 551 del ex código penal de Ecuador de 1971. 
que justifique estas decisiones. Sin embargo, pese a no existir fundamento que indique la eficacia de este planteamiento, se realizaron reformas que continuaron apelando a la severidad del castigo como mecanismo de prevención del delito y a la creación de nuevos tipos penales, intentando encontrar en el derecho penal la respuesta a problemas estructurales de la sociedad, olvidando que la naturaleza de esta rama del derecho es el castigo, no la solución de conflictos.

El castigo como tal constituye una actividad muy difícil de justificar, particularmente en situaciones de fuerte e inexcusable desigualdad, siendo ésta la razón por la que se requiere una aproximación crítica ${ }^{18}$. Es por esto que resulta difícil comprender la ligereza con la que se aplican medidas que carecen de bases que las justifiquen; y, al mismo tiempo, causan efectos negativos en las vidas de las personas privadas de libertad. Por citar algunos ejemplos que denoten la punitividad de nuestro código, se tipificaron aproximadamente 70 nuevos delitos con el COIP, cómo: apartheid, empleo de personas para mendicidad, entre otros; se agregaron y delimitaron nueve agravantes en las infracciones contra la integridad sexual y reproductiva, la integridad y la libertad personal ${ }^{19}$; y, en las reformas del año 2019, la pena por abuso sexual aumentó en un grado respecto de la agravante con menores y se incluyeron nuevos tipos penales como la instigación al suicidio.

Es evidente el camino que se ha trazado para combatir la criminalidad desde un ámbito completamente punitivo, así como también son evidentes los resultados obtenidos con solo levantar la mirada a nuestro sistema de rehabilitación y el creciente número de la población carcelaria. Esto reforzaría lo que tantas veces se ha planteado por diversos estudios de criminología y ciencias penales:

[...] no es la crueldad de las penas uno de los más grandes frenos de los delitos, sino la fiabilidad de ellas [...]. La certidumbre del castigo, aunque este sea moderado, hará siempre mayor impresión que el temor de otro más terrible, unido con la esperanza de la impunidad ${ }^{20}$.

Esto nos invita a cuestionarnos por qué no acudimos a otro tipo de alternativas para solventar los problemas relacionados con la prevención del delito. El mismo Beccaria nos ha dado luces respecto a dónde se podría iniciar, estableciendo que para que las penas sean eficaces

18 GARGARELLA, R. Castigar al prójimo: por una refundación democrática del derecho penal. Buenos Aires: Siglo XXI, 2019. ISBN: 9789876296793

19 Artículo 48 del Código Orgánico Integral Penal.

20 BECCARIA, C. De los delitos y las penas. Manuel Martínez Neira. Madrid: Universidad Carlos III de Madrid, 2015. ISBN: 978-84-89315-76-1 
respecto de efectos preventivos, deben imponerse con celeridad, [...] porque cuando más rápido se impone la pena, más fuerte quedará grabada en la mente de la persona la asociación de que a todo beneficio generado por un delito le sigue un mal, producto de una pena ${ }^{21}$.

El punto de Beccaria se debe comprender tomando en cuenta su posición. Él consideraba que el placer y el dolor son el motor de la acción humana; y, que el delito es el resultado de una elección racional realizada por las personas debido a la suma de beneficios y perjuicios posibles 22 . Por lo tanto, si el ofensor tuviese la certeza de que a su acción delictiva le vendrá una consecuencia mayor al beneficio que obtendrá, éste desistiría de cometer el delito.

Existen diversos estudios que ayudan a fortalecer el argumento a favor de la certeza por encima de la severidad, cuestionando los efectos de este último factor en relación con su función preventiva ${ }^{23}$; sin embargo, esto no es materia del presente estudio. Como bien se planteó en un inicio, aquí se quiere evidenciar que el aumento de penas no ha servido para reducir los índices de criminalidad.

De la inmutabilidad de las cifras en el tiempo se desprende la clara ineficacia de las soluciones planteadas; los números se mantienen o empeoran, siendo sencillo comprender que la solución no ha bastado para reducir el problema. Aún tenemos vigente una discusión que desde hace más de 200 años ha dado la razón a un solo lado: las políticas penales orientadas únicamente hacia la prevención de los delitos a través de la represión, han generado más violencia de la que pretendían resolver ${ }^{24}$.

21 BECCARIA, C. De los delitos y las penas. Manuel Martínez Neira. Madrid: Universidad Carlos III de Madrid, 2015. ISBN: 978-84-89315-76-1

22 BECCARIA, C. De los delitos y las penas. Manuel Martínez Neira. Madrid: Universidad Carlos III de Madrid, 2015. ISBN: 978-84-89315-76-1

23 Al respecto véase: GARLAND, D. Castigo y sociedad moderna. Buenos Aires: Siglo XXI, 2016. ISBN 968-23-2192-1; LARRAURI, E. La economía política del castigo. Barcelona: Mientras tanto, 2009. Págs. 131-135. ISSN 1695-0194; VASSALLO SAMBUCETI, E. Algunas reflexiones sobre el propósito del castigo. Lima: Advocatus, 2019. DOI: https://doi.org/10.26439/advocatus2012.n026.4114; MIRÓ LINARES, F. ¿Por qué cumplimos las normas penales? Sobre la disuasión en materia de seguridad vial. Sevilla: InDret, 2013. ISSN—e 1698-739X; CASTRO TOLEDO, J. Explorando los límites de la disuasión. Sevilla: InDret, 2021. ISSN 1698-739X; GÓMEZ-BELLVIS, A. La disuasión penal en el estado de alarma: sobre la eficacia de la amenaza del castigo de la desobediencia al confinamiento. Sevilla: InDret, 2020. ISSN—e 1698-739X, y, RANDO CASERMEIRO, P. Disuasión y piratería. Sevilla: InDret, 2019. ISSN 1698-739X; entre otros.

24 PRADO CHIRIBOGA, G. El aumento de penas y sanciones como un mecanismo en el control de la criminalidad en Ecuador. Quito: Universidad Andina Simón Bolívar, 2016. 
Es necesario señalar que las probabilidades de que estos efectos sean similares en otros delitos son muy altas debido a que se ha aplicado la misma solución como mecanismo de prevención y los índices de población carcelaria se han mantenido en aumento ${ }^{25}$. Sin embargo, correlación no implica causalidad, por lo que, debo enfatizar en la carencia de datos sobre denuncia y materialización de otros delitos, existiendo una necesidad urgente de recopilarlos para indicar con exactitud la ineficacia de lo ejecutado. Estos datos servirán también para determinar las causas exactas del deterioro de nuestro sistema de rehabilitación y el creciente número de nuestra población carcelaria. Si bien no se puede afirmar que es el alto punitivismo existente el único causante de estos problemas, tampoco se puede negar que sí es uno de los motivos que más los profundiza y agudiza.

\section{SISTEMA ALTERNATIVO DE PENAS}

Una vez que se ha evidenciado, en base a cifras y datos existentes, la ineficacia del endurecimiento de penas en uno de los delitos con mayor presencia en nuestra realidad; corresponde abordar la segunda temática del artículo: la necesidad de un sistema alternativo a prisión eficaz como posible solución ante la situación que afronta nuestro sistema de rehabilitación.

Es conocido que existe una tendencia marcada hacia la descarcelación, fundamentada principalmente en los efectos negativos que esta institución ha tenido en relación a los aspectos rehabilitadores de los condenados y su reinserción en la sociedad ${ }^{26}$; sumando el hecho de que tanto la igualdad, y el avance de un Estado se evidencian en el reflejo del uso de mecanismos de solución de conflictos alternos al derecho penal ${ }^{27}$.

25 Al respecto se puede observar el trabajo: PRADO CHIRIBOGA, G. El aumento de penas y sanciones como un mecanismo en el control de la criminalidad en Ecuador. Quito: Universidad Andina Simón Bolívar, 2016. Mismo en el que se analizó la incidencia del endurecimiento de penas en otros delitos como violación y asesinato.

${ }^{26}$ Véase: RIVERA, I. Descarcelación, principios para una política pública de reducción de la cárcel. Desde un garantismo radical. Valencia: Tirant Lo Blanch, 2017. Pág. 252. ISSN 0718-3399; y, CID, J. ¿Es la prisión criminógena? Madrid: Revista de Derecho Penal y Criminología UNED, 2007. ISSN 1132-9955

27 CID, J; Y, LARRAURI, E. Penas alternativas a la prisión. Barcelona: BOSCH casa editorial s.a., 1997. ISBN: 84-7676-403-0 
Las medidas alternativas a la prisión son sanciones dirigidas a una persona que ha realizado la adecuación de su conducta a un tipo penal y que no consisten en la privación total de libertad en una institución ${ }^{28}$, es decir, buscan el cumplimiento de la condena fuera de prisión por los efectos contraproducentes que pueden generarse en el uso de la misma. Nos referimos a penas - o sanciones- comunitarias cuando existen condenas no consistentes en la privación de libertad en prisión o en una institución psiquiátrica o centro de detención; e implican, en cierta medida, supervisión por un profesional. Además, bien se ha señalado que estas alternativas son un mecanismo que sirve para disminuir la presencia de esta institución, persiguiendo la consecución del principio de enfocar a la prisión como un último recurso ${ }^{29}$.

Las sanciones alternativas pueden ser de distintos tipos, todo depende del sistema penal ante el que se encuentre. En España, por ejemplo, pueden ser: trabajo en beneficio de la comunidad, localización permanente, multas y penas privativas de otros derechos ${ }^{30}$. La denominación de castigos comunitarios es más perteneciente a corrientes anglosajonas, mientras que, en países como España, se suele conocer a las mismas como alternativas a prisión.

Si bien sociedades con diferente tratamiento jurídico han intentado adoptar estas figuras que persiguen un menor uso de la punitividad estatal, a niveles prácticos nos hemos quedado cortos respecto a una efectiva y correcta aplicación de las mismas. Es aquí en donde resulta pertinente indicar que, así como se endurecieron las penas y se tipificaron nuevos delitos, también se introdujo por primera vez en nuestra legislación un sistema de figuras que da alternativas a prisión. Entre ellas se encuentran la suspensión de la pena y el trabajo en beneficio de la comunidad.

En este punto, debo advertir que me centraré estas dos figuras, en razón de que son las dos únicas sanciones alternativas a prisión reconocidas tanto por la legislación penal ecuatoriana, como la española.

28 CID, J; Y, LARRAURI, E. Penas alternativas a la prisión. Barcelona: BOSCH casa editorial s.a., 1997. ISBN: 84-7676-403-0

29 CID, J; Y, LARRAURI, E. Penas alternativas a la prisión. Barcelona: BOSCH casa editorial s.a., 1997. ISBN: 84-7676-403-0

30 BLAY, E., \&, LARRAURI, E. Community punishments in Spain: A tale of two administrations. Abingdon: Routledge, 2016. ISBN 9781315768489 


\section{IV.1. Contexto España: Suspensión de la pena y trabajo en beneficio a la comunidad}

\section{IV.1.A. Suspensión de la pena}

La institución de la suspensión de la pena es una de las herramientas más importantes de la política criminal moderna, la cual está orientada a la reinserción social de la persona privada de libertad con el fin de esquivar los efectos criminógenos de prisión. La suspensión de la pena consiste en la interrupción de la ejecución de la pena privativa de libertad, cuando la persona condenada cumpla determinados requisitos necesarios y se someta a ciertas condiciones $^{31}$. Esta alternativa es la de mayor arraigo en su entorno cultural. En España, el artículo 80 del Código Penal establece que los jueces o tribunales pueden dejar suspendida la ejecución de la pena privativa de libertad no superior a dos años, cuando se admita esperar que la ejecución de la pena no es necesaria para evitar la comisión de futuros delitos por parte del condenado.

El juzgador o tribunal debe valorar las circunstancias del delito, las circunstancias personales del condenado, sus antecedentes, la conducta posterior al hecho - siendo importante su esfuerzo por reparar el daño cometido- $\mathrm{y}$, sus circunstancias familiares y sociales; además, para acceder al beneficio de la suspensión, de manera general, se necesita que la pena no sea superior a dos años; haber delinquido por primera vez ${ }^{32}$ y haber satisfecho las responsabilidades civiles originadas por el delito, o comprometerse a satisfacerla; existiendo casos en los que pueden darse excepciones a estas condiciones ${ }^{33}$.

Así mismo, la legislación española reconoce la suspensión extraordinaria, la suspensión para drogodependientes y la suspensión por enfermedad incurable. Respecto a la primera, se indica que pueden existir situaciones en las que no concurran algunas de las condiciones establecidas para acceder a la suspensión, en concreto los requisitos de haber delinquido por primera vez y que la pena impuesta

31 GONZÁLEZ ZORRILLA, C. "Suspensión de la pena y "probation»". Penas alternativas a prisión. 1997. Sevilla: BOSCH casa editorial, 1997. Pág. 61. ISBN: 847676-403-0

32 Según lo establecido en el artículo 80 numeral 2 de Código penal español, en este requisito no se tendrán en cuenta condenas anteriores por delitos imprudentes o delitos leves, ni los antecedentes penales cancelados o debieran serlo en base a lo expuesto en el art. 136. Así mismo, se indica que no se tendrán en cuenta antecedentes penales correspondientes a delitos que por su naturaleza o circunstancias carezcan de relevancia para valorar la probabilidad de comisión de delitos futuros.

33 Véase el artículo 80 del Código penal español, numerales 3, 4, 5 y 6. 
no sea superior a dos años. Cuando se presenten estas situaciones se podrá acordar la suspensión de las penas de prisión que individualmente no excedan de dos años si las circunstancias personales del reo, la naturaleza del hecho, su conducta y el esfuerzo para reparar el daño causado así lo recomiendan. El código penal español señala que en estos casos la suspensión estará condicionada a la reparación efectiva del daño o la indemnización del perjuicio causado, conforme a las posibilidades físicas y económicas; o, al cumplimiento del acuerdo al que se hace referencia en el párrafo anterior. Así mismo, el código indica que el juzgador debe observar siempre que no se trate de un reo habitual, es decir, que no haya cometido tres o más delitos del mismo capítulo en un plazo no superior a cinco años y haber sido condenado por ellos. Además, en este tipo de suspensión, el juez debe imponer una de las medidas establecidas en los numerales 2 a o 3 a del art. 84, siendo estas: prohibición de establecer contacto con ciertas personas o miembros de un grupo determinado y mantener su lugar de residencia en un lugar específico ${ }^{34}$.

Respecto al segundo tipo de suspensión mencionado, se ha determinado que es aplicable a delitos con pena de hasta 5 años a personas que han delinquido a causa de su adicción a las drogas. Se condiciona a que la persona se mantenga en tratamiento de deshabituación. Las causas de revocación tanto de esta modalidad como de la anterior son las mismas que las determinadas para la suspensión ordinaria. Por último, la suspensión por enfermedad incurable aplica sobre cualquier pena, tiene lugar cuando el penado presente una enfermedad muy grave con padecimientos incurables y no se otorga si al momento de la comisión del delito el condenado ya tiene otra pena suspendida por el mismo motivo. Esta última se revoca por la comisión de un nuevo delito ${ }^{35}$.

El plazo de la suspensión puede ser de dos a cinco años para las penas privativas de libertad no superiores a dos años y tres meses a un año para penas leves ${ }^{36}$. La suspensión se resolverá en sentencia siempre que sea posible; en otros casos, al declararse la firmeza de la sentencia, el juzgador se debe pronunciar sobre la misma con la mayor anticipación posible previa audiencia de las partes. La suspensión comienza a computarse desde la fecha de la resolución que la concede ${ }^{37}$. Así mismo, se puede condicionar la suspensión al cumplimiento de prohibiciones y deberes como: 1) prohibición de

\footnotetext{
Véase los arts. 80 numeral 3 y 84 del Código penal español.

Véase art. 80.5 del Código penal español.

Véase art. 81 del Código penal español.

Véase art. 82 del Código penal español.
} 
acercarse a la víctima, sus familiares $\mathrm{u}$ otras personas que el juez considere apropiado, así como a sus domicilios, lugares de trabajo o lugares frecuentados por ellos; 2) prohibición de establecer contacto con determinadas personas; 3 ) prohibición de residir en un lugar determinado; 4) comparecer personalmente ante el juez o tribunal; 5) participar en programas de deshabituación al consumo de alcohol o drogas; entre otros ${ }^{38}$.

Es importante señalar que, en caso de incumplimiento de las prohibiciones, deberes o condiciones de forma grave y reiterada, el juez o tribunal puede revocar la suspensión y ordenar la ejecución de la pena. Sin embargo, cuando el incumplimiento no sea de carácter grave o de forma reiterada podrá tomar otras medidas ${ }^{39}$.

En este punto resulta relevante acotar algunos datos obtenidos que nos ayudan a dilucidar cuáles han sido los efectos de la aplicación de la suspensión y su acogida dentro del sistema penal español. En una investigación realizada bajo la coordinación de los profesores José Cid y Elena Larrauri, en la que se toma como muestra representativa las condenas impuestas en 1998 por los juzgados de lo penal de Barcelona ${ }^{40}$, se han logrado observar los siguientes escenarios:

- Cuando el ofensor no tiene antecedentes penales, el juez se decide preferentemente por la suspensión de la pena antes que la condena a prisión en una relación de $98.5 \%$ a $1.5 \%$.

- Cuando el ofensor tiene antecedentes cancelados o cancelables, el juez se decide preferentemente por la suspensión de la pena antes que la condena a prisión en una relación de $55.5 \%$ a $44.5 \%$.

- Cuando el ofensor presenta antecedentes posteriores, el juez se decide preferentemente por la pena de prisión antes que la suspensión de la pena en una relación de $44 \%$ a $56 \%$.

Así mismo, los autores recopilaron datos respecto a la totalidad de las penas privativas de libertad dictadas entre 1996 y 2003, realizando una distinción respecto a aquellas que fueron ejecutadas y aquellas que fueron suspendidas, arrojando los siguientes resultados:

38 Véase art. 83 del Código penal español, sería una figura similar a la suspensión "condicional" de la pena.

39 Véase art. 86 del Código penal español.

40 CID, JOSÉ; LARRAURI, ELENA; ESCOBAR, G; LAHOZ, J - LÓPEZ I FERRER; TÉBAR, M; VARONA, D. Jueces penales y penas en España (aplicación de las penas alternativas a la privación de libertad. Valencia: Tirant Lo Blanch, 2002. 


\begin{tabular}{cccc}
\hline Penas privativas de libertad ejecutadas y suspendidas en España entre 1996-2003 \\
\hline Año & $\begin{array}{c}\text { Total, penas priva- } \\
\text { tivas de libertad }\end{array}$ & $\begin{array}{c}\text { Penas privativas } \\
\text { de libertad ejecu- } \\
\text { tadas }\end{array}$ & $\begin{array}{c}\text { Penas privativas } \\
\text { de libertad suspen- } \\
\text { didas }\end{array}$ \\
\hline 1996 & 66.417 & $59.646(89,8 \%)$ & $6.771(10,2 \%)$ \\
\hline 1997 & 63.276 & $56.660(89,5 \%)$ & $6.616(10,5 \%)$ \\
\hline 1998 & 43.549 & $38,943(89,4 \%)$ & $4,606(10,6 \%)$ \\
\hline 1999 & 85.663 & $75.823(88,5 \%)$ & $9.840(11,5 \%)$ \\
\hline 2000 & 58.710 & $49.800(84,8 \%)$ & $8.910(15,2 \%)$ \\
\hline 2001 & 69.661 & $55.143(79,2 \%)$ & $14.518(20,8 \%)$ \\
\hline 2002 & 68.049 & $42.791(68,9 \%)$ & $25.258(37,1 \%)$ \\
\hline 2003 & 61.708 & $34.483(55,9 \%)$ & $27.225(44,1 \%)$ \\
\hline
\end{tabular}

Fuente: CID, J. La suspensión de la pena en España: descarcelación y reincidencia. Revista de Derecho Penal y Criminología. Madrid: UNED, 2005. Págs.- 223-235.

Por último, para aportar datos más recientes, el profesor Daniel Varona ha logrado determinar los siguientes puntos respecto a la aplicación de la suspensión de la pena en España ${ }^{41}$ :

- La mayoría de las penas de prisión impuestas en sentencia por los juzgados de lo penal son posteriormente suspendidas en un porcentaje que oscila el $70 \%$ y $80 \%$.

- La mayoría de suspensiones de pena de prisión se conceden en su modalidad ordinaria; es decir, sin otra obligación que la de no delinquir en el periodo de prueba.

- Existe una evolución respecto de anteriores investigaciones en la línea de aumentar la aplicación de la suspensión de la pena de prisión, cuestión que, al mismo tiempo, disminuye el porcentaje de penas de prisión impuestas que conllevan el ingreso del ofensor en prisión.

De estos datos se pueden identificar dos puntos claros: 1) Desde la introducción de la suspensión de la pena en la normativa penal española, los operadores de justicia han visto en ella una figura que puede servir como castigo adecuado para el ofensor, otorgándole

41 VARONA, D. "La suspensión de la pena de prisión: razones de una historia de éxito". Revista española de investigación criminológica, 2019. Madrid: Sociedad Española de Investigación Criminológica, 2019. Págs 27-31. ISSN: 1696-9219 
mayor confianza y cabida con el pasar de los años; y, 2) La utilización de esta figura por parte de los operadores del sistema de justicia penal deriva en una descongestión directa del uso de prisión como castigo.

En este punto resulta importante señalar que, pese a los datos expuestos anteriormente, la suspensión de la pena en España tampoco es un ejemplo para seguir completamente en aspectos prácticos. Como se verá más adelante, se ha tomado como punto de análisis para evidenciar de mejor forma las limitantes e incoherencias en la normativa ecuatoriana y los efectos positivos que resultan de su aplicación, pero esta figura presenta muchos problemas que han sido criticados por varios sectores doctrinarios; en especial desde las reformas del 2015 al código penal español.

Respecto a las reformas, se modificó la regulación de la suspensión y la sustitución a través de un sistema nuevo que tiene como principal característica la existencia de un régimen único de suspensión, en el cuál se determinan varias alternativas. ${ }^{42}$ Esto con el fin de dar a la suspensión de la pena mayor flexibilidad y facilitar su tramitación con mayor celeridad en la fase inicial de la ejecución de las penas ${ }^{43}$.

Una primera crítica realizada a las reformas del código penal español en relación con la suspensión de la pena, más que de fondo, es de forma. Al respecto se indica que existen inconsistencias y contradicciones en el texto modificatorio, mismas que atentan los fundamentos del principio de legalidad ${ }^{44}$. El derecho se transmite mediante palabras, con un discurso que será más eficaz mientras mejor estructurado, y más claro, sea al momento de expresarse.

La segunda crítica que se realiza está dirigida a un tema de mayor profundidad. En las reformas, en concreto en el texto del art. 84, se deja abierta la posibilidad de que el juzgador, en cualquiera de las

42 BARQUín SANZ, J., \& DIOS LUNA DEL CASTILLO, J. de. [2019]. Aplicación práctica de la suspensión y la sustitución de las penas privativas de libertad: una aproximación estadística. Revista De Derecho Penal Y Criminología, (10), 415-470. Recuperado a partir de http://revistas.uned.es/index.php/RDPC/article/ view/24554.

43 Exposición de Motivos de la Ley Orgánica 1/2015, de 30 de marzo, modificatoria de la Ley Orgánica 10/1995, de 23 de noviembre, del Código Penal Español.

${ }_{44} \mathrm{Al}$ respecto véase: BARQUíN SANZ, J., \& DIOS LUNA DEL CASTILLO, J. de. [2019]. Aplicación práctica de la suspensión y la sustitución de las penas privativas de libertad: una aproximación estadística. Revista De Derecho Penal Y Criminología, (10), 415-470. Recuperado a partir de http://revistas.uned.es/index.php/RDPC/ article/view/24554. 
modalidades de la suspensión, sean cuales sean las circunstancias del hecho y las personales del sujeto activo, pueda ordenar el cumplimiento de una pena sustitutiva; sin establecer algún criterio que permita al juez orientarse respecto a cuándo es procedente la sustitución y cuándo basta con la suspensión, generando ambigüedad e inseguridad jurídica ${ }^{45}$. Este cambio es sujeto a críticas debido a que de la redacción del texto se desprende que se permite la aplicación simultanea de dos penas sustitutivas reconocidas por la legislación penal española: la multa y el trabajo en beneficio de la comunidad ${ }^{46}$. Esto resulta preocupante porque podría presentar muchos problemas prácticos que afecten a los beneficiarios de estas figuras, por ejemplo: desde la non reformatio in peius se podrían debatir varios puntos tomando en cuenta que se estaría permitiendo la aplicación varios castigos, al mismo tiempo, sobre una sola conducta. Afectando directamente la naturaleza de estas figuras que tienen fines rehabilitadores.

Se puede observar la existencia de problemas en relación con la aplicación de esta figura en España, mismos que merecen ser tratados con profundidad para determinar puntualmente los errores y alcanzar soluciones loables ${ }^{47}$. Sin embargo, es importante destacar que esto no elimina los efectos positivos que se han generado de su aplicación en relación con el sistema de justicia penal y el sistema penitenciario, tal como se expuso en este apartado. Lo que sí generan, sin duda alguna, es una afectación que puede causar la reducción o errónea forma de aplicación de la misma, constituyéndose también como limitantes a los efectos positivos que podría dar esta figura.

\section{IV.1.B. Trabajo en beneficio de la comunidad}

Es importante conocer cómo funciona el trabajo en beneficio de la comunidad (TBC) en España, dado que, dentro del catálogo de penas alternativas, esta sanción puede ser la más apropiada para ejecutarse en lugar de la pena de prisión ante la materialización del robo,

45 FRANCO IZQUIERDO, M. La suspensión de la ejecución de las penas privativas de libertad en el código penal español: cuestiones controvertidas a las que se enfrentan los tribunales de justicia en su aplicación. [2017]. Bilbao, España. Universidad del País Vasco.

46 Véase art. 84 del Código Penal Español: "El Juez o Tribunal también podrá condicionar la suspensión de la ejecución de la pena al cumplimiento de alguna o algunas de las siguientes prestaciones o medidas"

${ }_{47}$ Para mayor desarrollo y una visión integral de los problemas jurídicos y prácticos que se presentan con la reforma de la ley 1/2015, de 30 de marzo, al Código penal español, puede verse: VALLE MARISCAL DE GANTE. Reforma del Código Penal de 2015. Foro: revista de ciencias jurídicas, [2015]. Madrid, ISSN 1698-5583. 
delito utilizado para el análisis de los efectos de la severidad de la pena en Ecuador; obviando el hecho de que la multa está históricamente orientada a su uso en delitos muy leves ${ }^{48}$.

La legislación penal española incluso prevé la posibilidad de aplicar esta pena como principal ante el delito de robo de uso de vehículo ${ }^{49}$. Además, tal como se mencionó antes, a nivel comparativo es una de las pocas posibilidades contempladas por la normativa penal ecuatoriana que tendría el juzgador para aplicar como alternativa a la prisión.

El servicio de trabajo comunitario, que requiere que los ofensores realicen un trabajo no remunerado, es una innovación penal relativamente reciente ${ }^{50}$. El trabajo en beneficio de la comunidad tiene su origen en Inglaterra y es tomado como una alternativa punitiva más dura que la multa y la probation ${ }^{51}$. El servicio comunitario surgió como resultado de la creciente preocupación por el aumento de la población carcelaria en la década de 1960. Análisis recientes muestran que los delitos para los que más se usa son los delitos contra la propiedad como hurtos o robos con fuerza en las cosas. Además, se afirma que el nivel de cumplimiento del trabajo en beneficio de la comunidad es alto, situándose como media entre el 85 y $90 \% 52$.

El objetivo principal de una orden de servicio comunitario es reintegrar al delincuente y prevenir futuras ofensas en la comunidad, a través de un trabajo positivo y exigente, ateniéndose a los requisitos disciplinarios ${ }^{53}$. En España, el trabajo en beneficio de la comunidad consiste en otorgar colaboración no retribuida en actividades de utilidad pública que pueden consistir en tareas de reparación de los daños causados o de asistencia o apoyo a la víctima ${ }^{54}$. Esta sanción se puede imponer como pena directa en determinados delitos

48 Véase: FARALDO-CABANA, P. Who Dares Fine a Murderer? The Changing Meaning of Money and Fines in Western European Criminal Systems. Social \& Legal Studies. 2016;25(4):489-507. doi:10.1177/0964663915618545.

49 Véase art. 244 Código penal español.

50 WORRAL, A., \&, HOY, C. Punishment in the community. Managing offenders, making choices. Cullomptom: William publishing, 2005. ISBN: 184392076X

51 CID, J. "El trabajo en beneficio de la comunidad". Penas alternativas a la prisión. 1997. Barcelona: BOSCH casa editorial s.a., 1997. Págs. 91-118. ISBN: 847676-403-0

52 CID, J. "El trabajo en beneficio de la comunidad". Penas alternativas a la prisión. 1997. Barcelona: BOSCH casa editorial s.a., 1997. Págs. 91-118. ISBN: 847676-403-0

53 WORRAL, A; Y, HOY, C. Punishment in the community. Managing offenders, making choices. Cullomptom: William publishing, 2005. ISBN: 184392076X

54 CONTRERAS, M. El potencial rehabilitador de la pena de trabajos en beneficio de la comunidad: revisión de la evidencia empírica y análisis de la percepción 
o ejecutarse dentro de la suspensión sustitutiva ${ }^{55}$ y tiene lugar solamente bajo el consentimiento del condenado ${ }^{56}$. Respecto a la segunda forma de aplicación, se ha establecido que los requisitos a cumplir son: a) Pena de hasta 2 años o que individualmente no exceda 2 años; b) No tener antecedentes dolosos o, en caso de tenerlos, que estos carezcan de relevancia para la comisión de nuevos delitos en el futuro $\left.{ }^{57} ; \mathrm{y}, \mathrm{c}\right)$ No ser reo habitual ${ }^{58}$. Siendo importante señalar que como condición obligatoria, debe existir el pago de la responsabilidad civil o el compromiso asumido; y, pueden determinarse condiciones facultativas como reglas de conducta.

Se debe realizar en el tiempo libre de la persona sin atentar contra su dignidad y debe ser dirigido a actividades de utilidad pública, siendo facilitado por la administración penitenciaria. Al condenado se le abonarán los gastos de transporte y manutención, además de otorgarle protección social mientras realice su actividad ${ }^{59}$. En caso de incumplimiento o problemas durante la ejecución, se puede acordar la misma de nueva manera en el centro establecido, enviar al penado a otro centro, $\mathrm{o}$, proceder por quebrantamiento de condena ${ }^{60}$.

Es importante señalar que, en España se presentó un aumento paulatino en su aplicación por parte de los juzgados y tribunales: en el 2006 se dictó esta medida alternativa 4.841 veces, en 2007 se dictó 13.803 veces, en 2008 se dictó 91.045 veces y en 2009 se dictó 109.574 veces $^{61}$; por lo que, podría decirse que su aplicación ha tomado fuerza.

Según la Dirección de Instituciones Penitenciarias, en Cataluña, la pena de trabajo en beneficio de la comunidad pasó de ser impuesta 681 veces en 1999 a 3.931 en 2005; y, al mismo tiempo, en

de una muestra de penados. VIII congreso nacional de investigación sobre violencia y delincuencia. Santiago de Chile: Fundación Paz Ciudadana, 2013. Págs. 243-263.

55 Véase art. 84.3 Código penal español.

56 CID, J. "El trabajo en beneficio de la comunidad". Penas alternativas a la prisión. 1997. Barcelona: BOSCH casa editorial s.a. 1997. Págs. 91-118. ISBN: 847676-403-0

57 Véase art. 80.2 Código penal español.

58 Véase art. 94 Código penal español.

59 CID, J. "El trabajo en beneficio de la comunidad". Penas alternativas a la prisión. 1997. Barcelona: BOSCH casa editorial s.a. 1997. Págs. 91-118. ISBN: 84-7676403-0

60 MELÉnDEZ, A. Penas comunitarias: Los trabajos en beneficio de la comunidad. Barcelona: Universitat Autónoma de Barcelona, 2019.

${ }_{61}$ BLAY, E., \&, LARRAURI, E. Penas comunitarias en Europa. Madrid: Editorial Trotta, 2011. ISBN: 978-84-9879-227-0 
toda España, pasó de 453 a 4.916 en el mismo período ${ }^{62}$. Los defensores del TBC justifican su aplicación desde el carácter regenerador de la figura; siendo éste constructivo y educativo ${ }^{63}$, como resultado del cambio que sufre el tiempo libre del penado en una actividad con que genera un gran arraigo social, como lo es el trabajo ${ }^{64}$, sin que esto signifique que esta pena carezca de un valor disuasivo, sino al contrario, ya que se lleva a cabo sin remuneración ni reducción alguna de la pena ${ }^{65}$.

Así mismo, en diversos estudios realizados respecto a los efectos rehabilitadores del TBC medido en relación a la reincidencia ${ }^{66}$, se ha logrado determinar lo siguiente:

[...] el índice de reincidencia de sujetos que habían cumplido la pena de TBC era inferior al que resultaba de aplicar los modelos de predicción al uso teniendo en cuenta la edad, sexo e historial criminal de los sujetos. Un sujeto que cumplía la pena de TBC tenía, así, menos posibilidades de cometer un delito en el futuro que un sujeto sometido a otra pena ${ }^{67}$.

Los diversos estudios apuntan a que el TBC reduce la reincidencia en aproximadamente 3 puntos porcentuales más que la prisión ${ }^{68}$; dejando entrever que es una de las sanciones alternativas con mayores efectos rehabilitadores. Por lo tanto, aquí se pueden concluir, nuevamente, dos puntos: 1) El trabajo en beneficio de la comunidad es una sanción alternativa que está encontrando crecimiento respecto de su aplicación en los sistemas penales, año tras año; y,

62 ALBALATE, J. "El trabajo en beneficio de la comunidad como alternativa a prisión: entre la aceptación y el rechazo”. Papers: revista de sociología, 2009. Barcelona: papers, 2009. Págs. 11-28. DOI: https://doi.org/10.3989/ris.2007.06.06

63 REDONDO, S.; GARCÍA, G.; \&, BLANCO, A. El costo de la justicia penal: privación de libertad y alternativas. Barcelona: Generalitat de Catalunya, 1997.

64 DOLCINI-PALIERO, E. Il carcere a alternative: la sanzioni sustitutive della detenzione breve nell'esperienza europea. Milán: Giufrré, 1989.

65 ALBALATE, J. "El trabajo en beneficio de la comunidad como alternativa a prisión: entre la aceptación y el rechazo”. Papers: revista de sociología. 2009. Barcelona: papers, 2009. Págs. 11-28. DOI: https://doi.org/10.3989/ris.2007.06.06

${ }_{66}$ Véase: RAYNOR, E. Straight thinking in probation (STOP). The Mid Glamorgan experiment. Probation Studies Unit Report n. 4. Oxford: Universidad de Oxford, 1997. NCJ Number 174781; LLOYD, C; MAIR, G; HOUGH, M. Explaining Reconviction Rates: A critic analysis. Londres: Homme Office Research Study, 1994. ISBN 011341117 0; y, MAY, C. Explaining Reconviction Following a Community Sentence: the role of social factors. Londres: Homme Office Research Study, 1999. ISBN 1840822198

67 BLAY, E. La pena de trabajo en beneficio de la comunidad. Barcelona: Universitat Autónoma de Barcelona, 2006. ISBN: 8469004565

68 BLAY, E. La pena de trabajo en beneficio de la comunidad. Barcelona: Universitat Autónoma de Barcelona, 2006. ISBN: 8469004565 
2) Los efectos rehabilitadores del TBC, en relación a la reincidencia, justifican su aplicación en la justicia penal; cuestión que incide directamente en el número de población carcelaria al ser una pena que se cumple fuera de prisión.

Al igual que en el análisis de la suspensión de la pena, aquí también resulta necesario traer a colación los principales problemas prácticos que presenta este tipo de castigo. En un primer punto, se indica que hay un gran problema en la aplicación de esta figura en relación con el requisito de consentimiento del penado para someterse a esta forma de castigo ${ }^{69}$. Al respecto se señala que muchas veces son los propios condenados quienes rechazan esta opción prefiriendo la multa; cuestión que es entendible partiendo de lo que implica cada elección. Me explico: si una persona tiene la posibilidad de elegir entre realizar un trabajo no remunerado, bajo ciertas condiciones y un tiempo determinado; o, simplemente pagar una cantidad de dinero como forma de castigo ${ }^{70}$; sin duda, la mayor tendencia será elegir la segunda opción por el esfuerzo que implica su cumplimiento. Considero que esta es una de las complicaciones más difíciles a tratar en el uso de esta figura.

Otros problemas que presenta el trabajo en beneficio de la comunidad son la falta de remuneración económica y la escasez de recursos o plazas para poder ejecutar el castigo. Sobre el factor de la remuneración, se indica que puede constituirse como un obstáculo para ejecutar correctamente la pena y conseguir sus fines. Este análisis se hace desde dos puntos: 1) Si el penado está en situación de paro laboral, el hecho de tener que realizar esta actividad como forma de pena le quitará el tiempo que necesita para buscar empleo, cuestión que puede influir negativamente en los efectos educadores o resocializadores del TBC; y, 2) La imposición de un TBC con tiempo prolongado, con jornadas de larga duración, puede resultar incompatible con la realización de una actividad laboral ${ }^{71}$.

69 Véase: GUTIERREZ GALLARDO, R. La pena de trabajo en beneficio de la comunidad: perspectiva dogmática. [2019]. Fundación Internacional de Ciencias Penales. Obtenido de https://ficp.es/wp-content/uploads/2019/03/Guti\%C3\%A9rrezGallardo.-Comunicaci\%C3\%B3n.pdf; y, BLAY, E. La pena de trabajo en beneficio de la comunidad. Barcelona: Universitat Autónoma de Barcelona, 2006. ISBN: 8469004565

70 Tomando en cuenta que tenga las posibilidades económicas de cumplir o realizar el pago.

71 BLAY, E. La pena de trabajo en beneficio de la comunidad. Barcelona: Universitat Autónoma de Barcelona, 2006. ISBN: 8469004565 
Así mismo, en base a que son "trabajos" que deben cumplir con ciertas características - utilidad pública- para la consecución de los fines de la pena - rehabilitación, reinserción y cierta expiación a la comunidad y la víctima por el daño ocasionado-, se comprende la limitación de actividades que podrán realizar las personas condenadas en este castigo. Además, se ha establecido que el TBC debe ser facilitado por el Estado, lo que le genera una obligación a este último de dar todas las condiciones necesarias para ejecutar la pena de la forma correcta.

Entonces, si se toma en cuenta que las actividades que pueden ejecutarse por TBC son reducidas, añadiendo las dificultades sociales y económicas que presentan su ejecución ${ }^{72}$, resulta lógico que exista desproporción entre las plazas disponibles y las personas condenadas a este castigo. Esto último se constituiría como una limitante directa de la aplicación de la figura ya que existirán casos en los que resulte adecuado - y necesario - el uso de esta forma de castigo, pero resulte inejecutable debido a la cantidad de plazas existentes.

Debo nuevamente destacar que esta última limitante influye sobre la posibilidad de aplicar la figura, no sobre los efectos de la misma. Se han podido observar los resultados positivos obtenidos cuando se ha logrado aplicar; lo que sugiere que se refuerce, más bien, su forma de aplicación.

\section{IV.2. Contexto Ecuador: suspensión condicional de la pena y trabajo en beneficio de la comunidad}

Suspensión condicional de la pena

En Ecuador la suspensión condicional de la pena, al igual que las penas alternativas a la prisión, y, el catálogo de penas aplicables a los delitos, se encuentran consagrados en el Código Orgánico Integral Penal ${ }^{73}$. Esta figura se introduce en la materia penal del país por primera vez en el año 2014, cuando entró en vigencia el código antes

72 Véase: BLAY, E. La pena de trabajo en beneficio de la comunidad. Barcelona: Universitat Autónoma de Barcelona, 2006. ISBN: 8469004565

73 El Código Orgánico Integral Penal es la normativa vigente a la actualidad en el Ecuador para la materia penal. Este cuerpo legal entró en vigencia en el año 2014, tras seis meses contados desde su publicación en el registro oficial el 10 de febrero del mismo año (2014), supliendo así, al ex código penal de 1971 y el código de procedimiento penal. 
mencionado. La misma establece una serie de requisitos que se deben cumplir para su aplicación, siendo estos:

- La pena privativa de libertad del tipo penal por el que se está juzgando, no puede ser superior a 5 años.

- El ofensor no debe tener otra sentencia en vigencia o un proceso en curso, ni se le debe haber aplicado una medida alternativa en otra causa.

- Se analizan los antecedentes personales, sociales y familiares de la persona, además de, la modalidad y la gravedad de su conducta, para conocer si indican que no existe la necesidad de ejecución de la pena privativa de libertad.

- La suspensión condicional no tiene cabida en los delitos contra la integridad sexual y reproductiva y violencia contra la mujer o miembros del núcleo familiar.

Es importante señalar que se aplica a la pena privativa de libertad impuesta en primera instancia, a petición de parte, en la audiencia de juicio o en las 24 horas posteriores; además, las condiciones, la forma de cumplimiento y el tiempo de la suspensión, son precisados por el juez $^{74}$. De igual forma, es necesario entender que el incumplimiento de las condiciones establecidas, o la transgresión del plazo acordado, derivan en la ejecución directa de la pena privativa de libertad ${ }^{75}$.

Se conoce que la aplicación de la suspensión condicional en Ecuador tiene cabida principalmente cuando la entrada en prisión del condenado puede causar detrimento en su proceso de rehabilitación, partiendo del hecho de que quienes cumplen su condena en prisión, tienen mayor dificultad de cumplir este propósito ${ }^{76}$, por lo que, el requisito de que el delito cometido no exceda a una condena de 5 años, encuentra su fundamento en que esta figura se aplica a delitos que no tengan un nivel alto de connotación social, ni el ofensor presente "alta peligrosidad". Sin embargo, me parece adecuado acotar que, como bien se señala ${ }^{77}$, el $80 \%$ de personas condenadas a

74 Artículo 630 del Código Orgánico Integral Penal (2014).

75 La ejecución de la pena privativa de libertad en caso de incumplimiento se encuentra consagrada en el artículo 632 del Código Orgánico Integral Penal (2014).

76 ELIZALDE, A. Aplicación de la suspensión condicional de la pena en la legislación penal ecuatoriana. [en línea] [25 de marzo de 2021]. Obtenido de: http:// repositorio.ucsg.edu.ec/handle/3317/10627.

77 ELIZALDE, A. Aplicación de la suspensión condicional de la pena en la legislación penal ecuatoriana. [en línea] [25 de marzo de 2021]. Obtenido de: http:// repositorio.ucsg.edu.ec/handle/3317/10627. 
prisión de hasta 5 años, no se rehabilitan; por el contrario, pasan a incrementar la estadística de nuevos delincuentes.

En relación al tipo penal que se tomó como partida para demostrar la ineficacia del endurecimiento de penas, me permito traerlo nuevamente al análisis para demostrar la incoherencia normativa que imposibilita la aplicación de alternativas. Dentro de la figura de la suspensión condicional se observó que uno de los requisitos principales para poder solicitar su aplicación es que la pena del delito no sea mayor a 5 años; por lo que, la aplicación de la suspensión y cualquier otra medida alternativa en este delito no es posible tomando en cuenta que el delito de robo sufrió un aumento en su pena, pasando de 1 a 5 años a una pena de 5 a 7 . Además, es necesario señalar que, como se observará adelante, solamente se podría acceder a un castigo comunitario bajo el otorgamiento de la suspensión al tratarse de un delito; y, dado que éste no cumple con los requisitos para que se le pueda aplicar la suspensión, se sobreentiende la imposibilidad de aplicar el trabajo en beneficio de la comunidad como alternativa a prisión.

$\mathrm{Al}$ haber entrado en vigencia al mismo tiempo, el aumento de penas en el delito de robo y las nuevas alternativas a prisión, el delito más cometido y denunciado en Ecuador, nunca tuvo la oportunidad de ser tratado con una sanción alternativa, impidiendo la valoración respecto a los beneficios en la rehabilitación de los ofensores que se someten a este tipo de castigo. Convirtiéndose en una limitante derivada de la falta de armonía y valoración normativa.

Debo señalar en este punto la inexistencia de datos que permitan realizar un análisis del porcentaje de aplicación de esta figura; así como, la falta de cifras respecto a los índices de reincidencia respecto de aquellos que hayan podido acceder a la suspensión condicional en Ecuador.

IV.2.A. Trabajo en beneficio de la comunidad o sanción comunitaria

En Ecuador se conoce al trabajo en beneficio de la comunidad como sinónimo de sanción comunitaria, misma que se encuentra consagrada en el catálogo de penas no privativas de libertad del artículo 60 del Código Orgánico Integral Penal. Tienen la misma esencia de las sanciones comunitarias establecidas en el resto de legislaciones, constituyéndose como una alternativa a la prisión que busca fortalecer los vínculos del ofensor con la sociedad y ejecutar el castigo que debe realizar dentro de ella, buscando así, su reintegro a la comunidad; Esto se transmite en que la persona que ha cometido un 
delito, visualice la existencia de un daño en los derechos de las personas y deba asumir las consecuencias de su conducta ${ }^{78}$.

Estas medidas alternativas se encuentran contempladas en ordenanzas municipales y el Código Orgánico Integral Penal, por lo que, pueden ser aplicables a quien ha cometido una contravención en lugar de hacer el pago de una multa, y a quienes hayan cometido un delito menor en lugar de ir a la cárcel. De esta manera, su aplicación tiene cabida en los dos tipos de infracciones reconocidas por el COIP, pero se accede a ella de diferente manera, dependiendo de si la conducta es una contravención o un delito.

Así se comprende que el uso del trabajo en beneficio de la comunidad en Ecuador puede darse de dos formas. La primera es en su condena directa impuesta por el juzgador cuando se encuentra ante contravenciones que contemplan el uso de su figura como pena principal, como lo son: infracciones de tránsito o escándalos públicos sin alarma, entre otros ${ }^{79}$. La segunda forma, destinada a los delitos, consiste en la aplicación de una sanción comunitaria como condición del juzgador al sentenciado, luego de haber concedido la suspensión condicional de la pena. El artículo 631 del COIP establece las condiciones en las que la persona sentenciada debe cumplir la suspensión condicional por el tiempo de su duración; justamente, en el numeral 5 del mencionado artículo, se prevé que debe tener un trabajo, profesión, oficio, empleo o realizar trabajos comunitarios. Esto conlleva a entender que, en el caso de los delitos, la sanción comunitaria es una pena accesoria de la suspensión condicional, y que, solamente está disponible para aplicarse cuando se ha accedido a esta última.

El servicio comunitario no es remunerado y no puede superar las 240 horas; además, no se puede realizar por más de 180 horas cuando se trata de una alternativa a la restricción de libertad de hasta 6 meses y no puede ser superior a 120 horas cuando se trate de contravenciones. Las principales reglas que debe seguir el juez para ordenarlas son: 1) Las tareas se deben ejecutar en beneficio de los vecinos o como forma de reparación a la víctima, no para realizar actividades que generen utilidad económica; 2) El tiempo destinado a pagar la sanción no puede interferir con el horario laboral,

78 ALBALATE, J. "El trabajo en beneficio de la comunidad como alternativa a prisión: entre la aceptación y el rechazo”. Papers: revista de sociología. 2009. Barcelona: papers, 2009. Págs. 11-28. DOI: https://doi.org/10.3989/ris.2007.06.06

79 Para mayor desarrollo, véase las contravenciones establecidas en el Código Orgánico Integral Penal con una pena principal aplicable consistente en trabajo comunitario, como por ejemplo las contempladas en el artículo 393 del mencionado cuerpo normativo. 
solamente después de la jornada o en fines de semana y feriados; 3) No deben excede tres horas al día, ni menos de 15 a la semana; 4) El servicio debe ser adecuado para personas con discapacidad que hayan sido condenadas ${ }^{80}$.

Como bien se puede observar, esta sanción alternativa ha sido destinada a infracciones menores, limitando su uso completamente. Tal como se señaló anteriormente, la posibilidad de aplicar esta figura a un delito como el robo es prácticamente nula por el aumento en la pena de este tipo penal. Lamentablemente, al igual que pasó con la suspensión condicional, no existen datos ni cifras que permitan realizar un análisis de uso y efectos de la aplicación de este tipo de sanción en Ecuador.

\section{CONCLUSIONES: LAS INCONGRUENCIAS}

El artículo 1 del Código Orgánico Integral Penal establece, como una de las finalidades del mismo, promover la rehabilitación social de las personas sentenciadas. De igual forma, en su artículo 52 determina que los fines de la pena son la prevención general para la comisión de delitos y el desarrollo progresivo de los derechos y capacidades de la persona condenada, aclarando que en ningún caso la pena tendrá como fin el aislamiento y la neutralización de las personas como seres sociales. En concordancia con esto, se indica también que las finalidades del sistema de rehabilitación social del país son: 1) La protección de derechos de las personas privadas de libertad atendiendo sus necesidades especiales; 2) El desarrollo de las capacidades de las personas privadas de libertad para que puedan ejercer sus derechos y cumplan sus responsabilidades cuando se encuentren en libertad; 3) La rehabilitación integral de las personas privadas de libertad; y, 4) La reinserción social y económica de las personas privadas de libertad ${ }^{81}$.

En este artículo se expuso la realidad del sistema de rehabilitación ecuatoriano, dentro del cual han existido innumerables vulneraciones de derechos humanos de las personas privadas de libertad, materializadas a través de la violencia interna, el desamparo estatal y la inexistencia de garantías, medios y recursos adecuados para su tratamiento. Por otro lado, la prevención general que se esperaba recibir con la vigencia del código no es visible; sino que, al contrario,

\footnotetext{
80 Artículo 63 del Código Orgánico Integral Penal.

81 Véase el art. 672 del Código Orgánico Integral Penal
} 
como se identificó con el delito de robo, los índices de criminalidad se mantienen. De esta forma podemos ver que lo ejecutado no es coherente con lo consagrado en la norma, quedando así en nada más que papel. Esto se evidencia aún más con las limitantes normativas que impiden un mayor uso de sanciones alternativas a prisión y la falta de voluntad, por parte de los jueces, en utilizarlas.

Estamos frente a un problema estructural de nuestra sociedad, no basta con la simple consagración de normas para conseguir resultados positivos, estas deben ser coherentes entre sí e ir acompañadas de capacitaciones y programas que permitan a los miembros del sistema de justicia penal ver, en estas alternativas, una verdadera solución a la criminalidad y la rehabilitación.

La ineficacia de la política criminal aplicada con la promulgación del COIP es palpable. Puede ser que el legislador haya incurrido en el error de asumir que la severidad de la pena traerá efectos preventivos; o, puede ser que haya asumido que el aumento de penas es lo que espera la ciudadanía, creyendo que son más punitivos de lo que en realidad son. Al respecto, Elena Larrauri ha advertido que se trata de una incomprensión de los políticos sobre la opinión pública: en los resultados de la encuesta internacional del delito, al preguntar qué condena impondrían a un joven de 21 años por robo por segunda ocasión, el $65 \%$ de la población considera mejor aplicar trabajo en beneficio de la comunidad en lugar de una pena de prisión ${ }^{82}$.

Así mismo, la carencia de cifras y datos que permitan estudiar el uso y los efectos de la aplicación de medidas alternativas en Ecuador imposibilita determinar en qué nivel éstas figuras ayudan a disminuir el uso de prisión en nuestra realidad. Sin embargo, es adecuado apreciar que estas sanciones no tienen gran cabida en nuestro sistema de justicia penal en razón de la alta cultura punitiva en la que convivimos. Basta con ver, tal como se señaló en el inicio del presente artículo, que los centros penitenciarios se encuentran con niveles elevados de sobrepoblación para comprender que el uso de estas figuras ha sido relegado; y que, al contrario, figuras que aumentan el uso de prisión, como la prisión preventiva, tienen mucha acogida en los operadores de justicia penal.

Es importante reconocer la ineficacia de las políticas punitivas ejecutadas para comprender de una vez que ese no es el camino que

82 LARRAURI, E. Populismo punitivo... y cómo resistirlo. Jueces para la democracia, Madrid: Jueces y juezas para la democracia, 2006. Págs. 15-22. ISSN 1133-0627 
debemos seguir para solventar la situación que se vive en el sistema penitenciario ecuatoriano. En otras realidades, como la española, en donde se aplican en mayor medida las sanciones alternativas, existen claros avances respecto a la disminución de la criminalidad en medida de reincidencia y al menor uso de prisión. Al respecto se señala que en 2020 prisiones cerró el año con la cifra más baja de reclusos de la última década, atribuyéndole este éxito a las reformas que tuvo el código penal español en referencia a la introducción de medidas alternativas y la suspensión condicional de la pena como tal ${ }^{83}$.

Pese a las notorias diferencias en los márgenes de aplicación de las sanciones alternativas estudiadas en el presente artículo, en España se sigue discutiendo que, por su éxito, estas medidas deberían tener un mayor espectro de aplicación ${ }^{84}$. Esto es importante debido a que en nuestra legislación penal las sanciones analizadas tienen un espacio de ejecución menor al español, dejando entender que no existe total confianza en estas figuras como respuesta a la criminalidad. Esto demuestra la resistencia a renunciar a soluciones completamente punitivas y aplicar nuevas alternativas que, como se pudo observar, tienen efectos positivos en la reincidencia y la reducción del número de ingresos en prisión.

Es aquí en donde corresponde cuestionarnos: ¿Por qué continuar con las mismas soluciones?, ¿No es hora ya de permitirnos alejarnos del populismo penal y el punitivismo? ¿Estamos listos y dispuestos para alzar a ver soluciones fuera de prisión?, ¿Por qué no damos un mayor margen de aplicación a las sanciones alternativas? Incluso se ha establecido que cuando las penas alternativas se recogen como penas directas y no como sustitutivas, los jueces tienden a aplicarlas en mayor medida ${ }^{85}$. Los esfuerzos realizados por algunas instituciones en eliminar las limitantes existentes deben ser comprendidos

83 Véase: ABC. Prisiones cierra 2020 con la cifra más baja de reclusos en la última década [en línea] [04 de abril de 2021]. Disponible en: https://www. abc.es/espana/abci-prisiones-cierra-2020-cifra-mas-baja-reclusos-ultima-decada-202012311027_noticia.html

${ }_{84}$ Véase: CID, J. "La suspensión de la pena en España: descarcelación y reincidencia”. Revista de Derecho Penal y Criminología. Madrid: UNED, 2005. Págs. 223229. ISSN 1132-9955; y, VARONA, D. "La suspensión de la pena de prisión: razones de una historia de éxito". Revista española de investigación criminológica, 2019. Madrid: Sociedad Española de Investigación Criminológica, 2019. Págs 27-31. ISSN: 1696-9219.

${ }_{85}$ BLAY, E. Nueve tópicos acerca del trabajo en beneficio de la comunidad: la necesidad de una discusión basada en conocimientos empíricos. Sevilla: InDret, 2007. ISSN 1698-739X 
y aplicados de forma sistemática por la totalidad de instituciones ${ }^{86}$, sí todos actuamos de forma menos punitiva el resultado beneficioso será mayor. Nuestra realidad penitenciaria necesita que respondamos de forma urgente estas interrogantes y, en el camino, darnos el trabajo de recopilar y reunir datos que permitan demostrar de forma clara los errores cometidos. Así se podrá trabajar en ellos y dar un nuevo aire al sistema de rehabilitación. Continuar ejecutando soluciones que derivan en el mayor uso de prisión, en sociedades con altos índices de desigualdad estructural, se constituye como una nueva forma de mantener latente la injusticia social.

Así mismo, se puede levantar la mirada a realidades cercanas (Colombia, Brasil, Perú, etc.) en las que se puede observar fácilmente que este problema afecta a toda la región. Esto nos da una señal de cuál es el camino que ha seguido la política criminal sudamericana y su consecuente fracaso reflejado en las cifras e incidentes que existen hoy en día en sus prisiones.

\section{METODOLOGÍA}

Tomando como partida y fundamento los objetos de estudio del artículo, resulta necesario entender que la metodología utilizada es cuantitativa al haber analizado datos de carácter secundario, es decir, ya existentes. Se hizo también un estudio de corte comparativo en relación con las medidas alternativas aplicables a distintas realidades y los resultados que han derivado de su aplicación en España.

Se utilizaron datos secundarios que permitieron analizar tres puntos en el presente artículo: 1) La situación actual del sistema penitenciario ecuatoriano; 2) Los efectos del endurecimiento de penas en el delito de robo; y, 3) Los efectos de la aplicación de la suspensión de la pena y el trabajo en beneficio de la comunidad en España.

86 La Corte Constitucional en la sentencia del caso No. 8-20-CN declaró la inconstitucionalidad de la prohibición de sustituir la prisión preventiva en infracciones con pena superior a cinco años del inciso primero del art. 536 del COIP; cuestión que elimina directamente una limitante normativa para reducir la presencia de personas en prisión. Sin embargo, días después entraron en vigor las últimas reformas al COIP en materia anticorrupción reforzando los tipos penales de peculado, cohecho, concusión, enriquecimiento ilícito; creando nuevos tipos penales; y, lo más preocupante, prohibiendo la aplicación de la suspensión condicional de la pena a estos delitos y el acceso a los beneficios penitenciarios de progresión de regímenes penitenciarios como semilibertad o prelibertad. Esta falta de armonía en las decisiones relacionadas con el sistema de justicia penal profundiza el problema carcelario del país. Por más que se esfuercen instituciones como la Corte, los resultados serán negativos mientras el Estado no adopte soluciones integrales y armónicas. 


\section{LIMITACIONES}

La principal limitante fue la escasez de datos existente en Ecuador respecto a índices de reincidencia, criminalidad, seguridad ciudadana y encuestas de victimización. Todas estas herramientas y datos sirven para tener un panorama claro de la realidad actual del sistema penitenciario y de rehabilitación; al no contar con ellos, palpar lo que sucede resulta muy difícil. Además, los datos existentes necesitan ser actualizados y ampliados a otros delitos. De esta forma se podrá evaluar de manera más específica todo lo ejecutado para reducir criminalidad, reincidencia y aumentar la percepción de seguridad.

Por otro lado, una segunda, pero menor limitante, fue el acceso a literatura física para el desarrollo del presente trabajo en razón de las prohibiciones establecidas por la pandemia COVID-19. Sin embargo, considero que se logró conseguir el sustento bibliográfico adecuado para la realización del presente artículo.

\section{BIBLIOGRAFÍA}

ABC. Prisiones cierra 2020 con la cifra más baja de reclusos en la última década [en línea] [04 de abril de 2021]. Disponible en: https:// www.abc.es/espana/abci-prisiones-cierra-2020-cifra-mas-baja-reclusos-ultima-decada-202012311027_noticia.html

Albalate, J. "El trabajo en beneficio de la comunidad como alternativa a prisión: entre la aceptación y el rechazo". Papers: revista de sociología, 2009. Barcelona: papers, 2009. Págs. 11-28. DOI: https://doi.org/10.3989/ris.2007.06.06

Barquín Sanz, J., \& Dios luna del Castillo, J. de. [2019]. Aplicación práctica de la suspensión y la sustitución de las penas privativas de libertad: una aproximación estadística. Revista De Derecho Penal Y Criminología, (10), 415-470. Recuperado a partir de http:// revistas.uned.es/index.php/RDPC/article/view/24554

BBC News Mundo [en línea] [23 de febrero de 2021]. Disponible en: https://www.bbc.com/mundo/noticias-america-latina-56186555.

BecCaria, C. De los delitos y las penas. Manuel Martínez Neira. Madrid: Universidad Carlos III de Madrid, 2015. ISBN: 978-84-89315-76-1

Blay, E., \&, Larrauri, E. Community punishments in Spain: A tale of two administrations. Abingdon: Routledge, 2016. ISBN 9781315768489 
Blay, E., \&, Larrauri, E. Penas comunitarias en Europa. Madrid: Editorial Trotta, 2011. ISBN: 978-84-9879-227-0

BLAY, E. La pena de trabajo en beneficio de la comunidad. Barcelona: Universitat Autónoma de Barcelona, 2006. ISBN: 8469004565

Blay, E. Nueve tópicos acerca del trabajo en beneficio de la comunidad: la necesidad de una discusión basada en conocimientos empíricos. Sevilla: InDret, 2007. ISSN 1698-739X

$\mathrm{CDH}, \mathrm{C}$. P. Informe hacinamiento y violencia son formas de tortura, situación de derechos humanos de población carcelaria y su familia en contexto de Estado de Excepción. Guayaquil: CDH, 2019.

CID, J., \& LARRAURI, E. Penas alternativas a la prisión. Barcelona, España: BOSCH casa editorial s.a., 1997. ISBN: 84-7676-403-0

CIDH, C. I. Informe sobre los derechos humanos de las personas privadas de libertad en las américas. Columbia: Organización de Estados Americanos OEA, 2011.

Castro Toledo, J. Explorando los límites de la disuasión. Sevilla: InDret, 2021. ISSN 1698-739X

CID, J. ¿Es la prisión criminógena? Madrid: Revista de Derecho Penal y Criminología UNED, 2007. ISSN 1132-9955

Cid, José; Larrauri, Elena; Escobar, G; LAHOZ, J - LÓPEZ I Ferrer; TÉBAR, M; VARONA, D. Jueces penales y penas en España (aplicación de las penas alternativas a la privación de libertad. Valencia: Tirant Lo Blanch, 2002.

CID, J. "El trabajo en beneficio de la comunidad". Penas alternativas a la prisión. 1997. Barcelona: BOSCH casa editorial s.a., 1997. Págs. 91-118. ISBN: 84-7676-403-0

CID, J. "La suspensión de la pena en España: descarcelación y reincidencia". Revista de Derecho Penal y Criminología. Madrid: UNED, 2005. Págs. 223-229. ISSN 1132-9955

CONTRERAS, M. El potencial rehabilitador de la pena de trabajos en beneficio de la comunidad: revisión de la evidencia empírica y análisis de la percepción de una muestra de penados. VIII congreso nacional de investigación sobre violencia y delincuencia. Santiago de Chile: Fundación Paz Ciudadana, 2013. Págs. 243-263.

Comisión Interamericana de Derechos Humanos, Principios y Buenas Prácticas sobre la Protección de las Personas Privadas de la Libertad en las Américas. Washington D.C.: Organization of American States, 2008. 
Corte IDH, Caso Neira Alegría y otros vs Perú, sentencia de 19 de enero de 1995; Corte IDH, Caso Juan Humberto Sánchez vs Honduras, sentencia de 07 de junio de 2003.

Corte IDH, Caso "Instituto de reeducación del menor" vs Paraguay, sentencia de 10 de noviembre de 2009.

Corte IDH, Caso De La Cruz. Flores vs Perú, sentencia de 18 de noviembre de 2004.

Corte IDH, Caso Tibi vs Ecuador, sentencia de 07 de septiembre de 2004.

DW [en línea] [01 de agosto de 2021] Disponible en: https://www.dw. com/es/un-muerto-y-cinco-heridos-por-enfrentamiento-enc\%C3\%A1rcel-de-ecuador/a-58719060

DEFENSORÍA DEL PUEBLO. Informe temático sobre la prisión preventiva desde la prevención de la tortura y otros malos tratos en el Ecuador, Quito: Defensoría del pueblo, 2018.

DolCINI-PALIERo, E. Il carcere a alternative: la sanzioni sustitutive della detenzione breve nell'esperienza europea. Milán: Giufrré, 1989.

ElizALDE, A. Aplicación de la suspensión condicional de la pena en la legislación penal ecuatoriana. [en línea] [25 de marzo de 2021]. Obtenido de: http://repositorio.ucsg.edu.ec/handle/3317/10627.

El Universo [en línea] [22 de julio de 2021] Disponible en: https:// www.eluniverso.com/noticias/seguridad/se-reportan-disturbios-enla-penitenciaria-del-litoral-nota/

Faraldo-Cabana, P. Who Dares Fine a Murderer? The Changing Meaning of Money and Fines in Western European Criminal Systems. Social \& Legal Studies. 2016;25(4):489-507. doi:10.1177/0964663915618545.

Franco IzQuiERdo, M. La suspensión de la ejecución de las penas privativas de libertad en el código penal español: cuestiones controvertidas a las que se enfrentan los tribunales de justicia en su aplicación. [2017]. Bilbao, España. Universidad del País Vasco.

FLORIAN, A. La prisión preventiva en el Ecuador, Quito: Defensoría Pública, 2018. ISBN 978-9942-9905-2-5

GK. ¿Por qué hay tanta gente en las cárceles del Ecuador? [en línea] [12 de febrero de 2021]. Disponible en: https://gk.city/2019/08/13/ tanta-gente-carceles-ecuador/

Gargarella, R. Castigar al prójimo: por una refundación democrática del derecho penal. Buenos Aires: Siglo XXI, 2019. ISBN: 9789876296793 
GaRland, D. Castigo y sociedad moderna. Buenos Aires: Siglo XXI, 2016. ISBN 968-23-2192-1

Gómez-BELlVIS, A. La disuasión penal en el estado de alarma: sobre la eficacia de la amenaza del castigo de la desobediencia al confinamiento. Sevilla: InDret, 2020. ISSN—e 1698-739X

GonZÁlez Zorrilla, C. "Suspensión de la pena y "probation»". Penas alternativas a prisión. 1997. Sevilla: BOSCH casa editorial, 1997. Pág. 61. ISBN: 84-7676-403-0

Gutierrez Gallardo, R. La pena de trabajo en beneficio de la comunidad: perspectiva dogmática. [2019]. Fundación Internacional de Ciencias Penales. Obtenido de https://ficp.es/ wp-content/uploads/2019/03/Guti\%C3\%A9rrez-Gallardo.Comunicaci\%C3\%B3n.pdf

Instituto Nacional de Estadísticas y Censos. Encuesta de victimización y percepción de inseguridad 2011 [en línea] [03 de marzo de 2021]. Disponible en: https://www.ecuadorencifras.gob.ec//documentos/web-inec/Victimizacion/Presentacion_principales_resultados.pdf

Instituto Nacional de Estadísticas y Censos. Denuncias de delitos de mayor incidencia [en línea] [ 17 de marzo de 2021]. Disponible en: https://www.ecuadorencifras.gob.ec/justicia-y-crimen/

LARRAURI, E. La economía política del castigo. Barcelona: Mientras tanto, 2009. Págs. 131-135. ISSN 1695-0194

LARRAURI, E. Populismo punitivo... y cómo resistirlo. Jueces para la democracia, Madrid: Jueces y juezas para la democracia, 2006. Págs. 15-22. ISSN 1133-0627

LLOYD, C; MaIR, G; Hough, M. Explaining Reconviction Rates: A critic analysis. Londres: Homme Office Research Study, 1994. ISBN 0113411170

MAY, C. Explaining Reconviction Following a Community Sentence: the role of social factors. Londres: Homme Office Research Study, 1999. ISBN 1840822198

MelÉndez, A. Penas comunitarias: Los trabajos en beneficio de la comunidad. Barcelona: Universitat Autónoma de Barcelona, 2019.

Ministerio Coordinador de Seguridad y Fiscalía General del Estado. Delitoscopio, informe de delitos [en línea] [15 de marzo de 2021]. Disponible en: https://issuu.com/fiscaliaecuador/docs/libro_fiscalia_horizontal_publicado. 
Miró LinaRes, F. ¿Por qué cumplimos las normas penales? Sobre la disuasión en materia de seguridad vial. Sevilla: InDret, 2013. ISSN-e 1698-739X

MORRIS, N. El futuro de las prisiones: estudios sobre crimen y justicia. Madrid: Siglo veintiuno, 1978. ISBN 13: 9789682300615

OEA. Informe sobre el uso de la prisión preventiva en las Américas, Columbia: OEA, 2013. ISBN 978-0-8270-6096-8.

Prado Chiriboga, G. El aumento de penas y sanciones como un mecanismo en el control de la criminalidad en Ecuador. Quito: Universidad Andina Simón Bolívar, 2016.

PRIMICIAS [en línea] [26 de febrero de 2021]. Disponible en: https:// www.primicias.ec/noticias/sociedad/carceles-tienen-deficit-setentapor-ciento-guias-penitenciarios/

Rando Casermeiro, P. Disuasión y piratería. Sevilla: InDret, 2019. ISSN 1698-739X

RAYNOR, E. Straight thinking in probation (STOP). The Mid Glamorgan experiment. Probation Studies Unit Report n. 4. Oxford: Universidad de Oxford, 1997. NCJ Number 174781

Redondo, S.; García, G.; \&, Blanco, A. El costo de la justicia penal: privación de libertad y alternativas. Barcelona: Generalitat de Catalunya, 1997.

RIVERA, I. Descarcelación, principios para una política pública de reducción de la cárcel. Desde un garantismo radical. Valencia: Tirant Lo Blanch, 2017. Pág. 252. ISSN 0718-3399

VARONA, D. "La suspensión de la pena de prisión: razones de una historia de éxito". Revista española de investigación criminológica, 2019. Madrid: Sociedad Española de Investigación Criminológica, 2019. Págs 27-31. ISSN: 1696-9219.

Vassallo SAmbuceti, E. Algunas reflexiones sobre el propósito del castigo. Lima: Advocatus, 2019. DOI: https://doi.org/10.26439/advocatus2012.n026.4114

Worral, A., \&, Hoy, C. Punishment in the community. Managing offenders, making choices. Cullomptom: William publishing, 2005. ISBN: 184392076X

Zalamea, D. Reporte del estado de la prisión preventiva en el Ecuador, Centro de Estudios de Justicia de las Américas, 2016. 